actually with their students ; and, of course, a large technical staff was available to handle intricate and bulky equipment. Both equipment and methods will have to be simplified drastically to adapt this medium for use in everyday instruction, and there is every expectation that this could be done. However, only practical experience under realistic conditions will show to what extent and how colour television can contribute to understanding and learning.

It may be of value to consider here the essential properties of colour television and how they might possibly be applied. Events and phenomena can be observed at a distance, even when direct vision is not possible. The moving image can be viewed either on large projection screens, or on smaller television receivers in any desired number of places, by large audiences, at the exact time that events are taking place. Fine detail, such as individual hairs on the back of the hand, and large scenes, such as big machinery in a laboratory, can be portrayed with equal ease. High-power microscopic examinations can be made with considerably higher brilliance than is possible with conventional projection microscopes. Preliminary experiments with endoscopes have proved that their use may well become a commonplace, as soon as the associated optical problems have been solved. Live presentation, films, slides and charts can be shown in immediate sequence, and indeed in any desired admixture.

The images from two or more television cameras can be presented in sequence or even side by side. It will thus be possible to correlate separate aspects of the same subject or to contrast similar phenomena by using more than one camera in quite different locations, as, for example, in a laboratory and in a hospital ward.

Perhaps the most important difference from normal visual records such as diagrams, lantern slides and motion picture films is the fact that a live action is shown on the television screen at the exact moment when it happens. Apart from any other considerations, the psychological effect of this upon a student body may prove to be considerable. Whereas a film is rigid in its construction and presentation and cannot easily be arrested, the television demonstration is entirely under the lecturer's control. He can direct the demonstrator through a two-way radio link, he can ask for an alternative presentation of the same subject or for a repetition when he feels that this would be of greater benefit to the students. Mistakes and defects can be rectified immediately, a process which may in fact add to the value of a demonstration, by emphasizing its immediate and local character, and thus imparting to it a liveliness and personal nature often absent from films. Each demonstration cen be varied according to the lecturer's wishes and according to the existing knowledge of his students. Participation by the audience can be used where appropriate, for students can both hear and speak to the demonstrator who is with the camera.

Many will maintain that the motion picture film can be used as effectively and more economically. A brief consideration of this contention will expose its fallacy. Even if funds could be raised to establish and maintain sufficient film production units to make films of all the many subjects which can be shown by television, fow teachers would have the time required for drafting the initial treatment and for supervising the scripting, rehearsing, shooting and editing of such films. Even if all these films could be made, they would neither fit in with the ideas of other teachers, nor could they possibly be equally effective for different types of audiences. Some 'date' quickly and there are inevitable delays between preparation and exhibition.

Such handicaps do not apply to television. The lecturer discusses with his assistant what he wishes to demonstrate. The camera is placed in position, and the lecturer can direct and control the proceodings as and when he requires them while talking to his students. This demonstration can be as simple or elaborate as he himself may wish.

The use of good colour, a live presentation, the magnification of small detail for large audiences, the juxtaposition of different events or phenomena separated in space, participation by the audience, and complete control by the lecturer can be regarded as the main characteristics which might be exploited. What effect, in terms of understanding and learning, might this have on students? Which type of student will derive the greatest benefit from colour television and at what stage of his learning? Which teaching situations and which disciplines are most likely to benefit from its use? How should it be used to its best advantage ? Finally, is the total effect economically worth while? The answers to these questions can only be established satisfactorily when a centre consisting of many different interests and types of student, both undergraduate and postgraduate, is prepared to underteke a full and unbiased investigation of the method. No one will be optimistic enough to imagine that colour television can solve all problems of teaching, nor will any responsible teacher wish to interpose an elaborate electronic device between himself and his class where the normal direct approach can do all he wishes. Nevertheless, experience already shows that television demonstration may permit valuable additions to the content of teaching in many medical subjects, especially by presentation to large audiences of things it is rarely possible to show even to a handful of students. Doubtless, present views and expectations will be modified, and unsuspected potentialities discovered, when it becomes possible to make a full exploration in the working conditions of a medical centre. The results of such an experiment might prove to have far-reaching effects on education, not only in university circles, but also in schools and perhaps even on television broadeasts to the general public.

A colour sound film recording of the demonstration and a booklet published by Marconi's Wireless Telegraph Co. in collaboration with the Illustration Department of Guy's Hospital Medical School are available.

C. E. ENGEL

ROGER WARWICK

\section{AUTOMATION IN THE POST OFFICE}

IN moving the second reading of the Post Office and Telegraph (Money) Bill in the House of Commons on December 5, the Postmaster-General, Mr. E. Marples, said that during the next two years the Post Office would be spending about $£ 180$ million on capital equipment, of which $£ 105$ million would be by way of depreciation and ploughed back by the Post Office. Of this sum, more than $£ 167$ million would go to telecommunications, $£ 6$ million to tolegraphs-mostly 'Telex' - and $£ 7$ million to postal 
services. Amplifying the White Paper (see p. 71 of this issue), Mr. Marples, who doubted whether there had been purposeful direction of science and shrewd timing of applied science in the past, explained how in 1958 the saving of $£ 2$ million would be achieved in wages as well as at least $f 10$ million-worth of equipment which would have been scrapped under the old system. To secure the maximum use of the $£ 150$ million-worth of buried wires, which is increasing at the rate of $£ 11$ million a year, the Post Office is trying to bring the automatic line concentrator into operation as fast as possible, and in 1960 it is hoped to have the first all-electronic exchange in operation at Highgate Woods, as a result of the work of the Joint Electronic Research Group, a partnership between the Post Office and private enterprise. By putting in extre repeaters every three miles, it will be possible to make much better use of the existing cosxial cables, either doubling the number of conversations or providing a television channel.

Dealing with the postal services, Mr. Marples said that the procedure in sorting is essentially the same as that used one hundred years ago ; of the total cost of the postal services of $£ 120$ million, man-power accounts for 70 per cent. Of that total, sorting accounts for $£ \mathbf{4 0}$ million and delivery for $£ 30$ million. The first electronic sorting machine is already in operation at Southampton, and another, the first of a further twenty, should soon be available at Norwich. This development, which is well in advance of the rest of the world, is due to the scientists at Dollis Hill Research Station. It requires for its application a standard envelope, and Mr. Marples emphasized the importance not only of co-operation, particularly with the United States and Canada, in research, but also of public opinion. He said he is starting a scientific survey to find out what the public expect and want from the postal services and how far they are prepared to co-operate, for example, by using a code number for the address. Mentioning the International Committee of Postal Studies, Mr. Marples said that as a result of a visit by the Deputy Postmaster-General of the United States last summer, a team of five Post Office officials has studied mech. anization in Canada and in the United States. He had also appointed a committee, with Sir Leonard Sinclair as chairman, "to advise the PostmasterGeneral on the future place of the inland public telegraph services as part of the communication facilities of the United Kingdom", and he was seeking to encourage co-operation with private industry particularly in telecommunications. Help was being given by the Council for Industrial Design in standardization of telephone exchange equipment and telephone kiosks. Referring to the human problems of automation, after a tribute to the co-operation of the trade unions, Mr. Marples said that he had appointed the general secretary of the Union of Post Office Workers and the chairman of the staff side of the Post Office non-engineering Whitley Committee to the policy committee advising him on mechanization.

In replying to a question in the debate about cable-ships, the Assistant Postmaster-General, Mr. $K$. Thompson, said that the new two-way Atlantic cable to be laid in a fow years, as a result of an agreement with Canada, would be a new plasticcovered cable developed by Post Office engineers and the cable company. British two-way rigid repeaters would provide sixty conversation channels in the single cable, compared with thirty-six in the present double cable.

\section{MEDICAL USES OF IONIZING RADIATIONS}

GOLLOWING on the publication of the British and American documents setting out the Hazards to Man of Nuclear Energy, the United Nations Organization set up a Scientific Committeo on the Effects of Atomic Radiation. This Committee invited the International Commission on Radiological Protection and the International Commission on Units and Measurements to consider how best to arrive at reliable data for estimating the doses received by different parts of the human body-by individuals, and in the aggregate by large population groups-due to medical use of ionizing radiation. A study group, under the joint chairmanship of Prof. Rolf Sievert and Dr. Lauriston Taylor (chsirmen, respectively, of the two International Commissions), decided to spread the work as widely as possible. It was divided among five groups of experts drawn from fourteen countries-Austria, Cansda, Columbia, Czechoslovakia, Denmark, France, Germany, Italy, Norway, Sweden, Switzerland, the United Kingdom, the United States of America, and Uruguay.

The genetic hazard is of primary importance, and the data when accumulated will be used for assessing the significant dose per annum to the gonads of any population. A study group of the World Health Organization, which reported earlier this year, considered the possibility of registering systematically doses received by all individuals, but this proposal proved to be unrealistic. There would be too great a margin of error, and too great an expenditure of man-power and of money. There would be difficult legal and psychologicel consequences. There are, however, certain classes of persons, and certain routine procedures, for which, by a widespreed expert sampling survey, sufficiently accurate records can be obteined. The undertaking is by no mesns a light one. The data available from half a dozen countries, now publishod in Physics in Medicine and Biology, 2, No. 2 (1957), in some eighteen tables, prove to be difficult of collation; they disclose wide differences of estimated gonad dose. In Denmark and the United Kingdom it is given as about 25 mrad., in Sweden 40 mrad. and in the United States something nearer $100 \mathrm{mrad}$.

The group recommends an extensive survey, preceded by a pilot preliminary survey. It sets out the desiderats for obtaining uniformly reported information from various countries. These include classifications of age groups, the anatomical type of examination, the radiological type, and the gonad dose per examination for male, female and foetus. In estimating the dose from the internal use of radionuclides, a factor should be introduced for 'parenthood expectation' for the average patient. It is of interest that, as had boen found with other surveys, even the pertial investigation so far carried out in Great Britain has already led to a reduction of the gonad dose by adoption of the recommenda. tions included in the last report of the International Commission on Radiological Protection, and the evidence from expert measurement of the actual doses delivered. The means recommended to this end include protective devices for the gonads, a minimum film-focus distance, increased tube-housing protection, permanent filters of at least $2 \mathrm{~mm}$. aluminium equivalent on all diagnostic tubes, the use of higher-voltage techniques, exposure counters 